\title{
A CIÊNCIA E OS VALORES HUMANOS: REPENSANDO UMA TESE CLÁSSICA
}

\author{
Alberto Cupani \\ U niversidade Federal de Santa Catarina \\ cupani@cfh.ufsc.br
}

\begin{abstract}
Resumo: No seu artigo "Science and human values" (1960), C.G. Hempel analisou a relação entre enunciados científicos e julgamento de valor, sustentando que os últimos não podem ser pressupostos pelos enunciados científicos nem deles derivados. Embora reconhecesse a influência de valorações na escolha da atividade científica e em certos aspectos da metodologia, $\mathrm{H}$ empel enfatizava que as valoraç̧̃es não têm lugar em absoluto no conhecimento científico como tal, e finalizava mostrando que o progresso científico pode causar mudanças em atitudes de valoração, ainda que não possa em rigor fundamentálas. N este trabal ho indago se a transformação da filosofia da ciência operada na segunda metade do século vinte, junto com as contribuições da sociologia do conhecimento e da história da ciência, modifica o diagnóstico de H empel. Como este assunto é muito amplo, a minha abordagem é inevitavelmente parcial.
\end{abstract}

Palavras-chave: Carl G. Hempel, ciência e valores, valores na ciência, conhecimento e valoração.

Há mais de quarenta anos, no seu artigo "Science and human values" (1960), redigido dentro do espírito da filosofia da ciência prékuhniana, C. G . H empel sustentava, de maneira típica, a impossibilidade de que juízos de valor categóricos pudessem ser deduzidos de, ou pressupostos por, afirmações científicas. Admitia H empel, contudo, que a atividade científica implica valorações das preferências dos cientistas e valorações instrumentais inerentes à metodologia. Para ele, o avanço do conhecimento científico pode conduzir a modificar posições axiológicas, embora não possa refutá-las.

$N$ esse período detempo quenos separa da publicação daquele artigo, a filosofia da ciência mudou, abrindo-se a considerações históricas, sociais, psicológicas eculturais. A sociologia do conhecimento 
científico e a história da ciência e os science studies têm submetido à análise crítica a atividade científica, prestando particular atenção aos interesses (e correspondentes val orações) que a influenciam, os quais podem de resto ser muito variados: econômicos, sociais, políticos etc. M ais recentemente, a crítica feminista procura mostrar que a empresa toda da ciência moderna está impregnada de valores "androcêntricos" e que não faltam autores a denunciar a secreta vinculação do saber científico, pretensamente neutro, com o afã de controlar a natureza. Por sua vez, H empel não incluiu em seu artigo - talvez por considerar o assunto como óbvio - os valores relativos ao denominado ethos da ciência, nem se mostrou sensível à possibilidade de que o conhecimento produzido pela ciência pudesse ser definido de outra maneira.

A té que ponto esse quadro de análise notavelmente mais amplo da questão em pauta modifica o diagnóstico hempeliano?É 0 que tratarei de examinar neste artigo. A literatura a esse respeito é certamente enorme. Limitar-meei a confrontar a posição hempeliana com a de alguns trabalhos que podem representar uma modificação, acrescentando algumas reflexões finais sobre a relevância do tipo de análise efetuado por Hempel.

\section{A índole do enfoque hempeliano}

C abe notar, antes de tudo, que H empel abordava a questão aqui analisada, entendendo por "valores" aquelas preferências enunciadas em forma de imperativos ou de enunciados incondicionais, e indagando se eles podiam de al gum modo estar "pressupostos" pela ciência. Hempel partia da classificação das valorações em juízos categóricos de valor (conforme o esquema: "x é bom", ou "devese fazer $x$ ") e juízos instrumentais de valor ("se se quiser al cançar $x$, deve-se fazer $y^{\prime \prime}$ ). O s primeiros, em razão de não serem enunciados descritivos, ${ }^{1}$ não podem ser verificados cientificamente, nem podem ser derivados de enunciados científicos (os quais são descritivos), a não ser que seja pressuposto um outro enunciado valorativo. $0 \mathrm{~s}$ 
segundos constituem na verdade enunciados descritivos condicionais (regras de ação), que são em princípio passíveis de teste. Como regras de procedimento, eles podem, ou bem contribuir para o estabelecimento de enunciados científicos, ou bem indicar a maneira de aplicar esses conhecimentos. Por outra parte, $\mathrm{H}$ empel lembrava que o teste de qualquer hipótese ou teoria nas ciências empíricas é geralmente inconclusivo, desde o ponto de vista lógico, incluindo assim um "risco indutivo", vale dizer, a possibilidade de que as afirmações correspondentes sejam fal sas. $\mathrm{Na}$ análise hempeliana, 0 que estava em causa era então a presença e legitimidade, na ciência, de juízos categóricos de valor, seja como elementos que contribuem para a val idade do conhecimento científico, seja como conseqüências legítimas deste último.

\section{VALORES COMO MOTIVAÇÕES}

H empel reconhecia que tais valorações intervêm por ocasião da escolha da atividade científica e, ainda, dos temas de pesquisa, sendo neste sentido "pressupostas" pela prática profissional, isto é, admitia valorações categóricas em nível de motivações individuais dos agentes de atividade científica. Não obstante, $\mathrm{H}$ empel não considerava a possível presença de tais valorações como motivos sociais da atividade científica. Tampouco o fez num trabalho posterior (H Em PEL, 1983) dedicado ao mesmo assunto. Por motivações sociais entendo aqui aquelas que levam uma sociedade a permitir e a estimular uma dada atividade. Talvez essa aparente omissão se devesse à - provável - convicção hempeliana de que a produção de conhecimento científico, por ele definido como um "corpus de informação confiável, amplo eteoricamente sistematizado" (H EM PEL, 1960, p. 93), que seja explicativo e permita predizer (H EM PEL, 1983, p. 91), fosse obviamente desejável em qualquer sociedade. Em todo caso, essa convicção tem sido criticada, entre outros, ${ }^{2}$ por pensadores alarmados pelo potencial de domínio e destruição natural do saber científico prolongado em tecnologia. Leiss (1972) explora o modo 
como a idéia da possibilidade (e quem sabe até o dever) de o homem "conquistar a N atureza", "idéia possivelmente absurda" (Leiss), acabou tornando-se óbvia no lapso que vai de Francis Bacon até o Iluminismo. Para Leiss, além denão ser óbvia, a valorização da ciência como atividade que conduz única e seguramente ao progresso humano opera como uma ideologia que oculta o caráter contraditório da ciência, capaz tanto de libertar quanto de escravizar o ser humano. (O u melhor, de permitir o domínio de uns seres humanos sobre outros de maneira cada vez mais eficaz.) M ais radical ainda (e aliada à crítica da submissão das mulheres em particular) é a censura do cultivo da ciência de Carolyn M erchant (1990), para quem a substituição da visão orgânica do mundo, própria das culturas antiga e medieval, pela cosmovisão mecanicista, longe de ser celebrada, deve ser denunciada como a paulatina morte da natureza aludida no título da sua obra.

Igualmente crítica da "ciência baconiana", porém mais sutil na sua argumentação, é a anál ise feita por Lacey (1999) da pretensão, própria da ciência moderna, de revelar "a realidade tal como ela é em si mesma", uma pretensão presuntivamente provada pela sua eficácia tecnológica. Segundo Lacey, a moderna ciência natural tem uma "afinidade el etiva" com o que ele denomina "metafísica materialista". Essa doutrina consistiria em acreditar que o mundo está constituído por objetos e processos governados por leis universais, dos quais podem ser reduzidos todos os fenômenos investigados (inclusive aqueles do âmbito humano). U ma tal metafísica fornece uma compreensão dos objetos e eventos do mundo no que diz respeito às suas possibilidades de serem manipulados e, assim, controlados. Esse tipo de ciência, que exclui sistematicamente todo fenômeno vinculado à experiência humana "vulgar" e se apóia em evidências impessoais, preferentemente quantitativas, obedeceria, para Lacey, a uma oculta decisão social impulsionada por uma valoração. Tratar-se-ia da valoração suprema conferida pela mentalidade moderna ao controle da natureza, que faria com que tãosomente sejam formuladas e testadas aquelas teorias que possam 
conduzir a esse objetivo, de maneira cada vez mais ampla e eficaz. Lacey admite que o teste das teorias, isto é, a decisão relativa à sua validade, está (ou pelo menos, deve estar) regida exclusivamente por valores epistêmicos. Nisso consistiria a "imparcialidade" da ciência, responsável pela sua eficácia. N ão obstante, isso não exclui que a escolha das teorias (tanto inicialmente quanto na presença de alternativas) e do tipo de evidência empírica que será considerada legítima possa sofrer a influência de valorações não-epistêmicas (sociais). A "estratégia materialista" da ciência moderna (ou seja, o paradigma que, segundo Lacey, governa a atividade científica) estaria assim comprometida com (pelo menos) um valor social, embora sua presença não pudesse ser detectada no nível do teste das teorias. D esse modo, a ciência, mesmo sendo imparcial, não seria neutral. ${ }^{3}$

U m argumento semelhante pode ser encontrado nas críticas feministas à ciência moderna. Conforme elas (ver, por exemplo, $\mathrm{H}$ arding, 1993), a escassa participação - ainda hoje - das mulheres na atividade científica não apenas evidenciaria os preconceitos de uma sociedade que combina diversos tipos de discriminação (social, cultural, racial, sexual), mas também sugeriria que os próprios parâmetros do conhecimento científico (racionalidade, objetividade, universalidade) refletem uma cosmovisão androcêntrica. A "racionalidade" e suas supostas manifestações: a "frieza" emotiva, o rigor, a impessoalidade e a isenção foram considerados, desde 0 século XIX, como características "masculinas", opostas a outras presuntivamente "femininas", tais como a delicadeza, a emotividade, a suavidade, a capacidade de intuir e a sensibilidade para com as outras pessoas (H ARDING, 1993, p. 68). O bviamente, as características "masculinas" teriam sido consideradas (avaliadas) como superiores, adequadas para o autêntico conhecimento do mundo. D esse modo, a política da ciência e a sua epistemologia reforçar-se-iam reciprocamente: a segregação das mulheres seria "natural". A inda que não se admita esse caráter geral da ciência moderna, ${ }^{4}$ a perspectiva feminista reivindica a descoberta de que as pesquisas científicas aparentemente rigorosas se revelam impregnadas por preconceitos 
sexistas. $\mathrm{Na}$ biologia, na antropologia e na sociologia, o olhar feminista crê detectar que a descrição dos objetos, a interpretação dos dados e a escolha de hipóteses estão influenciadas por uma implícita valoração apriorística do ponto de vista masculino. E, certamente, as próprias noções do "masculino" e do "feminino", especialmente quan do concebidas como "naturais", estariam traindo o caráter "androcêntrico" da ciência. É importante frisar que, conforme a crítica feminista, as distorções antes mencionadas não aparecem apenas em casos de ciência "má" (isto é, de pesquisa descuidada ou fraudulenta), mas em episódios de investigações normais, reputadas de "objetivas" e "isentas" (LongINo, 1983).

As críticas antes mencionadas constituem, pois, um alargamento de uma das dimensões em que H empel reconhecia a presença de valorações na ciência. N o entanto, não se trata apenas de uma ampliação do ponto de vista hempeliano, porque as teses antes mencionadas atingem a noção da ciência como "livre de valores" (Weber): se aquelas teses forem corretas, a ciência neutra ou isenta em nível individual ou grupal não seria incompatível com o compromisso axiológico da ciência genericamente considerada.

\section{VALORAÇÕES NO CONHECIMENTO E NA METODOLOGIA}

A pós reconhecer a presença de valorações como motivações da pesquisa científica, $\mathrm{H}$ empel analisava a sua possível presença no conhecimento produzido por aquela atividade. 0 conhecimento científico, dizia H empel, não pressupõe valorações categóricas, nem no sentido de implicá-las logicamente (o que não é possível), nem no sentido de que contribuam para a validade dos enunciados científicos, validade essa que depen de exclusivamente das evidências empíricas e teóricas.

Nada mudou, certamente, quanto à observação de que val orações categóricas não podem estar logicamente implicadas por enunciados científicos. Contudo, se a inclusão de "ébom descobrir a verdade" (o exemplo é de H empel) não contribui para a validade 
de uma dada conclusão científica, esses e outros julgamentos de valor (como "deve-se pensar logicamente") parecem pressupostos no sentido de serem condições de significado da operação realizada (ou seja, da argumentação). Aqui, se os juízos de valor não têm "pertinência lógica", eles parecem ter pertinência semântico-pragmática. ${ }^{5}$ Por outro lado, a passagem ilícita entre o que é e o que deve ser pode ser evitada (ou encoberta), caso a premissa de valor seja formulada como enunciado descritivo. H esse (1980) assinala casos em que crenças acerca de como era desejável que o mundo fosse (ou não), influenciaram a formulação de teorias. Por exemplo, a crença na perfeição da simetria esférica conduziu à tese de que os céus eram esfericamente simétricos (p. 2). 0 utras cren ças-valorações que tiveram papel análogo foram a convicção de que o homem é único e superior entre os organismos, e a de que a mente é desvalorizada caso seja considerada como um mecanismo natural. H esse sustenta que essas crenças foram filtradas, com o passar do tempo, pelo critério pragmático do sucesso em predizer, que seria segundo ela decisivo para consagrar a validade das teorias (p. 4).

Isso nos leva ao terceiro "lugar" onde podemos buscar juízos de valor na ciência, vale dizer, na metodologia. H empel reconhecia que, na justificação das regras para a aceitação das hipóteses e teorias, precisa-se de valorações. Como, em todo caso de regra decisória, devemos atribuir valores aos resultados alternativos previstos. No caso da ciência aplicada, as valorações têm a ver com a finalidade pretendida; na ciência pura, a valoração pressuposta diz respeito ao conhecimento almejado, tal como antes definido, e ao propósito de aceitar hipóteses verdadeiras e rejeitar as falsas, evitando o risco de aceitar as falsas ou rejeitar as verdadeiras (H EM PEL, 1960, p. 92).

U m artigo relativamente recente (D ougLAS, 2000) retoma essa problemática, questionando a convicção, comum a H empel e a outros estudiosos do assunto, como M cM ullin (1983), de que 0 cientista que faz pesquisa básica precisa levar em consideração apenas as conseqüências epistêmicas do possível erro ao aceitar hipóteses, teorias ou conclusões. Essa limitação, conforme D ouglas, passa por 
alto a autoridade que a ciência e os cientistas têm atualmente, bem como a sua interven ção em tomadas de decisão práticas (D ou GLAS, 2000 , p. 563). C ontudo, mais importante ainda seria perceber que os cientistas tomam decisões ao longo da pesquisa (ou seja, antes de chegar a resultados), sendo então os únicos que podem pensar nas conseqüências não-epistêmicas (sociais, em sentido amplo) que decorreriam de estarem errados. D ouglas endossa a tese de Longino (1990), segundo a qual as escol has científicas envolvem "suposições básicas" (background assumptions) que podem incluir juízos de valor. ${ }^{6}$ D ouglas assinala três momentos da pesquisa em que se correo "risco indutivo" e se procede a uma opção, a saber: na escolha de uma dada metodologia; na colheita e caracterização dos dados, e na interpretação deles (p. 565). H empel está correto, admite D ouglas, ao afirmar que, ao determinar se uma hipótese está ou não confirmada pela evidência disponível (isto é, na apreciação da relação lógica entre essas instâncias), juízos de valor não intervêm. Não obstante, tanto na determinação de qual seja a evidência disponível como na escolha de suposições básicas, apela-se para valorações que influenciam assim indiretamente na pesquisa.

D ouglasilustra sua tese com exemplos retirados de uma pesquisa sobre 0 câncer, envolvendo experimentos com ratos nos quais se injetou uma substância tóxica (D ou G LAS, 2000, p. 568 ss.). A pontando as opções metodológicas imprescindíveis (tal como o nível de relevância estatística adotado), bem como as dificuldades para identificar amostras claramente positivas ou negativas (dificuldade evidenciada na discrepância entre os peritos), D ouglas sustenta que os cientistas se viram obrigados a considerar as conseqüências nãoepistêmicas ea decidir um equilíbrio entre elas (possível dano à saúde contra custo de produção para as empresas), comprometen do-se com valorações. A argumentação de D ouglas é, a meu ver, convincente.

Diferente é o caso de uma outra autora (INTEMAnN, 2001), que al ega que na própria definição do objeto científico pode haver julgamentos de valor implícitos. Segundo ela, na caracterização da depressão como uma doença (e não como uma mera síndrome) 
revelada por sintomas que afetam funções centrais ou essenciais ao bem-estar das pessoas, estariam implicados um ou vários juízos de valor acerca do que os pesquisadores entendem por vida humana "boa". Intemann rebate possíveis contra-argumentos, no sentido de que o que se deve entender por vida "boa" possa ser enunciado descritivamente, seja mediante uma definição técnica de "saúde", seja mediante uma determinação estatística da "normalidade" ( $p$. 510-511). U m outro exemplo de valorações que condicionariam 0 raciocínio científico estaria dado, ainda segundo Intemann, pelos casos em que se considera aceitável a evidência previamente aduzida por um pesquisador para que ela seja verificada. N esses casos, estarse-ia subentendendo um juízo de valor relativo à confiabilidade daquele pesquisador. Desse modo, segundo a autora, o valor epistêmico atribuído às evidências estaria atrelado a julgamentos de valor nãoepistêmicos, os quais, contudo, deveriam ser justificáveis (p. 517). C reio que as análises de Intemann (às quais remeto o leitor) não são satisfatórias para demonstrar a intraduzibilidade de certos juízos de valor "apreciativos" a juízos de valor "caracterizadores" (NAGEL, 1979, p. 444). ${ }^{7}$ Intemann, ao que parece, ignora essa distinção e não se dá conta de ela está inclusa na sua (correta) cobrança de que os juízos de val or sejam "justificáveis". Tampouco parece dar-se conta de que, mesmo nessa hipótese, sempre deveríamos pressupor algum juízo de valor categórico como premissa (tal como H empel, certamente, admitia), e que essa última valoração é amiúde nãoepistêmica. Em outras palavras: apesar das deficiências da argumentação de Intemann, seu trabalho e o deD ouglas mostram que valorações não-epistêmicas podem ser circunstancialmente necessárias para estabelecer conclusões científicas.

\section{Sobre a Fundamentação CIEntífICA de VALORAÇõeS}

A pós haver excluído a possibilidade de que juízos categóricos de valor possam estar logicamente implicados por conclusões científicas, H empel abordava, sem denominá-la como tal, a "falácia 
naturalista" (E. M oore): a impossibilidade lógica de validar (ou desqualificar) enunciados valorativos mediante 0 saber científico. A ciência, ensinava $\mathrm{H}$ empel, não pode justificar nem refutar enunciados normativos, porém pode ajudar-nos resolver problemas morais fornecendo informações sobre a factibilidade e as conseqüências de al go a que nos propomos (e valoramos). Pode também esclarecer-nos sobre o funcionamento dos fatores psicológicos e da dinâmica social, fazendo com que superemos a comum tendência de considerar absolutos os nossos critérios morais. D essa forma, a ciência pode fazer com que mudemos de opinião sobre valorações categóricas (H EM PEL, 1960, p. 93 ss).

M ais uma vez, não é possível negar que H empel tivesse razão. D outrinas morais e, mais amplamente, atitudes valorativas categóricas (ou a sua rejeição) não podem ser dedużdas de puros enunciados científicos (ou, em geral, de enunciados descritivos). Entre estes últimos e osimperativos (morais, sociais, culturais) continua havendo um hiato. Gostaria, contudo, de comentar duas tentativas de diminuir a importância desse hiato inegável.

Ao teorizar sobre questões éticas, Bunge (1989, p. 304 ss.) prega a conveniência de transcrever os imperativos em sentenças ("Faz X!", por exemplo, equivaleria a "Tens o dever de fazer x"), de tal modo que se possa testálos e argumentar criticamente sobre eles. Dessa maneira obteríamos "regras de inferência axiológica" (ou seja, não propriamente lógica), que permitiriam passar legitimamente de certos enunciados a outros. Tendo como único princípio moral (não demonstrado, porém plausível) o enunciado "É correto desfrutar da vida e ajudar a viver", seria possível sustentar argumentos como o seguinte:

Se A (é o caso, ou é feito), então $B$ (resulta).

$B$ é bom (ou correto) e, em comparação, melhor (ou mais correto) do que A I A é bom (ou correto) [i.e., A deveria ser (o caso, ou feito)]

(Bunge, 1989, p. 301). 
0 autor dá a essa forma argumentativa a denominação modus vollens.

Segundo Bunge, a sua proposta reconhece a existência de um hiato entre o é e o deve, porém nega que seja um abismo para a argumentação racional. A aplicação óbvia ao nosso tema éa de que 0 avanço da compreensão científica do mundo acarreta conseqüências valiosas (ou valoradas), e não meramente influencia as nossas valorações.

A proposta de Bunge é certamente duvidosa como defesa de um novo tipo de argumentação válida. ${ }^{8} \mathrm{M}$ enos convincente ainda resulta 0 acréscimo do autor ao afirmar que 0 pretenso abismo entre 0 é e 0 deve é franqueado praticamente toda vez que um organismo age para satisfazer necessidades ou desejos, "transformando um deficiente é (atual estado de coisas) num satisfatório deveria (futuro estado de al gum sistema de que o agente faz parte)" (p. 306). Porém, a análise de Bunge pode ajudar a entender (como no caso anteriormente citado da aparente passagem do deve ao é analisado por H esse), de quemodo se tornam convincentes posições axiológicas supostamente sustentadas pela ciência.

I dêntico comentário merecem as reflexões do historiador Loren G raham (1981, p. 31), que sugere que a tese da separação entre fatos e valores, sobretudo a partir de G. E. Moore, foi 0 reflexo de uma atitude de defesa dos valores tradicionais com relação ao progresso científico. ${ }^{9} \mathrm{G}$ raham acrescenta que os progressos científicos estão contribuindo para uma compreensão naturalista da maneira como os seres humanos sustentam seus valores e conclui:

O fato de que continue não sendo possível derivar um "deveria" de um "é" pode chegar a carecer de importância caso se tornar claro que todo "deveria" possuído por seres humanos reais teve uma origem e um desenvolvimento naturalista, explicável mediante a ciência. (G RAHAM, 1981, p. 32) 


\section{U MA APARENTE OMISSÃO: O ETHOS DA CIÊNCIA}

Como já antecipei, $\mathrm{H}$ empel não se referiu em seu artigo ao ethos da ciência (MERTON, 1964, p. 543 ss), talvez por considerar indiscutível a necessi dade da sua obser vância para alcançar o objetivo da ciência. Os "imperativos institucionais" constitutivos do ethos, tais como a falta de preconceito ("universal ismo"), o espírito crítico ("ceticismo metódico"), o desinteresse (relativo a objetivos nãocognitivos) e a exposição pública do conhecimento ("comunitarismo"), funcionariam como regras (vale dizer, como juízos instrumentais de valor) em relação ao objetivo de produzir um conhecimento confiável, amplo e sistematizado. ${ }^{10}$ Poder-se-ia objetar que eles não constituiriam propriamente valorações, nem teriam um caráter extra-epistêmico. Não obstante, eles constituem imposições da ciência, como instituição social, sobre os pesquisadores. São, em palavras de Merton, "mores" da ciência, "um conjunto de prescrições tanto morais como técnicas", imperativos que "são moralmente obrigatórios, não somente porque são eficazes do ponto de vista técnico, mas também porque são considerados justos e bons" (p. 543).

Sem embargo, a realidade e a efetividade do ethos têm sido questionadas. A Iguns sociólogos afirmam que ele existe antes como elemento retórico do que como ingrediente efetivo na produção do conhecimento científico (ver por exemplo, M uLKAY, 1991). U m estudo muito citado (MITRoFf, 1974) sugere que os cientistas obedecem circunstancialmente a normas e contranormas (por exemplo, ao comunitarismo e ao segredo). E o famoso livro de Feyerabend, A gainst method (1975), inclui a tese de que, se G alileu não houvesse infringido a ética profissional (por exemplo, ocultando evidências que prejudicavam a teoria copernicana), a ciência não teria progredido como o fez. Além do mais, o compromisso cada vez maior da pesquisa científica com instituições extracientíficas (burocráticas, industriais, militares) parece estar modificando a atitude científica (ZIMAN, 1996), um assunto ao qual pretendo voltar. 
Em resumo, parece discutível que o objetivo da ciência possa ser alcançado tendo o ethos como condição necessária. No meu estudo "Acerca do ethos da ciência" (Cu PANI, 1998), procuro demonstrar que as críticas aos "imperativos" de M erton e à sua escola não são suficientes para provar que o ethos seja supérfluo ou contraproducente para atingir o melhor tipo possível de conhecimento objetivo, sendo pelo contrário as infrações ao ethos (tais como 0 segredo, a fraude ou o predomínio de interesses não-cognitivos) mais claramente prejudiciais. No entanto, a minha posição supõe a distinção entre aquele conhecimento e o conhecimento produzido pela ciência efetiva (mais contingente ainda do que a sua "reconstrução lógica"), e também o não-questionamento da ciência que possibilita o controle da natureza.

\section{ConsideraçõES FINAIS}

Das análises mencionadas infere-se que a tese de $\mathrm{H}$ empel permanece substancialmente correta, em seus aspectos lógicos, ${ }^{11}$ ao mesmo tempo que manifesta uma certa limitação ao não suspeitar que o conhecimento científico poderia estar prefigurado por valorações sociais e culturais. Essa prefiguração se acrescentaria às razões tradicionalmente admitidas da contingência do saber científico empírico (essencialmente, a inexistência de uma lógica indutiva, as dificuldades da observação e o experimento).

Por outra parte, a contingência mencionada acentua-se, em nível metodológico, pelosindícios (aqui, osfornecidos pelo trabalho de D ouglas) de que val orações não-epistêmicas podem intervir para estabelecer conclusões cognitivas aceitáveis. Tudo isso convida a refletir sobre a caracterização hempeliana do conhecimento científico (variável certamente independente na sua análise), como um corpus de informação "confiável" (reliable). Essa confiabilidade supõe, na análise do autor, que as conclusões científicas resultam de uma correta (isto é, logicamente válida) vinculação das idéias com as evidências. ${ }^{12}$ Q uero dizer: se um conhecimento é aceito como 
científico, vale dizer, como confiável, isso implica que ele resulta de inferências não alteradas por outros fatores (como valorações extracientíficas). Não é outro o sentido do raciocínio hempeliano: se quisermos alcançar um tal conhecimento, então as regras de decisão devem ser tais e quais (H EM PEL, 1960, p. 93). Porém - e como H empel certamente não negaria - não podemosa rigor inferir que a aceitação da existência efetiva de um conhecimento aceito não incluiu valorações.

A anterior observação pode ser formulada também da seguinte maneira: a contingência tradicional mente reconhecida no conhecimento científico aumenta à medida que se admite, não apenas que as conclusões da ciência factual são sempre (e inevitavelmente) provisórias, aproximadas, fundamentadas só até um certo ponto e impossíveis de serem totalmente checadas, mas também que a ciência se torna amiúde superficial, trivial, descuidada, fragmentária ou direcionada (sem incluir a ciência fraudulenta), em razão da interven ção de fatores, tais como a urgência de publicar, as pressões burocráticas, a necessidade de financiamento e o peso dos interesses. É praticamente impossível que resultados tão contingentes assim não contenham juízos de valor. E, na medida em que a ciência "acadêmica" dá lugar à ciência industrial (ou "tecnociência"), menos motivos temos para esperar que os resultados científicos oficiais sejam neutros.

$N$ ote-se ademais que 0 argumento hempeliano supõe como factível um conhecimento cuja confiabilidade (aproximada) só tenha a ver com as limitações do raciocínio lógico e da prática observacional e experimental. M as, e se esse objetivo não fosse factível, tal como se revelou, por exemplo, o objetivo de que a ciência fornecesse conhecimentos certos? (LAUDAN, 1984). 0 raciocínio hempeliano poderia ser mais bem formulado da seguinte maneira: se existir um conhecimento assim confiável, el e não poderia implicar julgamentos de valor extracientíficos. 0 ra, daí parece passar-se, quando se confia na "ciência livre de valores", a supor que esse conhecimento de fato existe. ${ }^{13}$ Diante dessa dificuldade, compreendese a mudança de 
enfoque da filosofia da ciên cia da tradição kuhniana, que se interessa mais pelo conhecimento queé efetivamente considerado como aceito pela comunidade científica, ${ }^{14}$ e que indaga as razões pelas quais é tido como "confiável". A tese de Hempel pode ser também reconsiderada, de acordo com o enfoque da nova filosofia da ciência, no que diz respeito ao fato de que a ciência não pode validar nem refutar juízos de valor. Poder-seia argumentar que, se a ciência não pode sustentar logicamente as valorações, ela o está fazendo praticamente pela sua inserção no sistema produtivo, governamental e militar. ${ }^{15}$ Valorações tais como "a economia deve visar o lucro", "é lícito desenvolver indefinidamente a tecnologia" ou "a vida humana deveser administrada" ilustram atitudes sociais geralmente não questionadas na sociedade moderna e amplamente sustentadas mediante informação científica e produtos tecnológicos. Reciprocamente, valorações, tais como "a natureza (ou a vida) é sagrada", "a guerra deveria ser suprimida" ou "deveríamos prescindir do supérfluo", parecem desautorizadas pelo progresso (?) científico-tecnológico.

É claro que o próprio Hempel não estava longe da anterior observação, ao admitir que, embora não pudesse fundamentar valorações absolutas, o conhecimento científico podia contribuir para mudá-las. Não deixa de ser irônico que o avanço científico possa conduzir a mudar também a valoração social da própria ciência. ${ }^{16} \mathrm{E}$ não me refiro apenas aos receios que a ciência suscita em função das aplicaçõestecnológicas. O s sociólogos e antropólogos da ciência têm intenção de fazer um trabalho científico (BLOOR, 1991). Se eles tiverem razão - e os resultados das suas pesquisas forem corretos -, essa ciência "demasiado humana" em que eles parecem empenhados em revelar talvez não seja merecedora de tanta estima e de tantas esperanças.

Em todo caso, essa necessidade de atender à ciência real poderia sugerir que a análise mais importante para a questão que explicitamente norteava a análise de $\mathrm{H}$ empel não fosse a análise lógica... a não ser para quem seinteressasse puramente pelas relações 
lógicas entre nossas crenças. H empel, com efeito, perguntava-se se não seria possível resolver os problemas morais acarretados pelo desenvolvimento científico, "por meio dos métodos objetivos da ciência moderna" (H EM PEL, 1960, p. 82). U ma análise filosófica, mas não puramente lógica, como a sugerida pelas reflexões anteriores, poderia chegar à mesma conclusão hempeliana, porém por diferentes razões. U ma delas bem poderia residir em que, como alguns suspeitam, a ciência não é a solução dos nossos problemas sociais porque faz parte deles.

\section{SCIENCE AND HUMAN VALUES: RETHINKING A CLASSICAL THESIS}

A bstract: In his article "Science and human values" (1960), C. G. H empel analyzed the relationship between scientific propositions and value judgments and defended the view that the latter cannot be presupposed by, or drawn from, the former. Although he admitted that values influence upon the choice of scientific activity and on some aspects of scientific methodology, Hempel emphasized that values have absolutely no place in scientific knowledge as such. He ended his article by showing that scientific progress may cause changes in stances relating to values, even if it cannot justify those stances. In this paper, I inquire whether the transformation of Philosophy of Science which took place in the second half of the twentieth century, together with the findings of Sociology of Knowledge and H istory of Science, modify Hempel's views. Since this subject matter is very broad, my approach is inevitably partial.

Key words: C arl G. Hempel, science and values, values in science, knowledge and value judgments.

\section{Notas}

1. Certamente, numa concepção não-metafísica dos predicados axiológicos.

2. Aludo aqui a críticas sobre o perigo da ciência para a religião, a "vida espiritual" ou para a "cultura".

3. Isso teria conseqüências práticas importantes: longe de poder ser aplicada indiferentemente a qualquer contexto social, acarretando conseqüências benéficas (como pensam os partidários da ciência enquanto fator de progresso), a ciência só 
poderia funcionar em contextos compatíveis com o seu espírito ou ao preço de eliminar tudo quanto a ele se opusesse.

4. Externado por outras autoras como S. Bordo (The flight from objectivity, 1987) e a já mencionada C. M erchant.

5. Estou apelando aqui para al go análogo às regras da "pragmática transcendental" (A pel) ou "universal" (H abermas). Rescher (1984, p. 237) argumenta em sentido parecido.

6. Segundo Schaffer (1996, p. 90), uma outra autora, esses "princípios extra-empíricos de julgamento" científico incluiriam, além de valorações, compromisso prévio com teorias, crenças de sen so comum, convicções metafísicas, práticas metodológicas heurísticas e virtudes pragmáticas (tais como a simplicidade.

7. M cM ullin (1983) faz uma diferença entre "valorar" e "avaliar", de maneira análoga.

8. Se não se trata de uma dedução (nem de uma indução, obviamente), não se percebe qual seria a natureza dessa inferência, que tampouco é considerada por Bunge como uma abdução, por exemplo (nem poderia sê-lo).

9. G raham observa que, durante os séculos XVII eXVIII, todos os argumentos sobre o "desígnio" para provar a existência de D eus eram de fato uma defesa de posições axiológicas, com base, supostamente, em conhecimentos relativos a fatos. 0 próprio H ume, o primeiro a denunciar a ilegitimidade de passar do "é" para o "deve", estava interessado em combater a moralidade baseada na religião, mas não a convicção de que a moralidade pudesse estar conectada com a natureza humana. Graham observa também que a enunciação da "falácia naturalista" por $M$ oore coincide com a época (finais do século XIX e começos do século XX) em que 0 avanço da biologia parecia acarretar 0 ateísmo (Graham, 1981, p. 31).

10. "Os imperativos institucionais ('mores') derivam da meta em vista e dos métodos". M erton (1964, p. 563) caracteriza esse 
conhecimento ("certificado") como contituído de "predições empiricamente confirmadas e logicamente congruentes".

11. Estou certamente me limitando à lógica clássica.

12. Inclui-se aí naturalmente a inferência probabilística.

13. Radnitzsky (1979) chega a considerar pleonástica a expressão "ciência livre de valores". M eu ponto de vista pode ser comparado à crítica kantiana ao argumento ontológico.

14. A isso corresponde o interesse, necessariamente mais restrito, da sociologia do conhecimento, em indagar o conhecimento tido por aceito ou válido por determinada comunidade profissional.

15. C abe lembrar que as valorações não precisam ser formuladas como juízos, podendo ser antes vivenciadas, encarnadas em práticas sociais enas instituições. Ver a excelente análise de Lacey (1999, cap. 2)

16. H empel colocava a valoração da ciência dentro de um esquema condicional, porém é quase óbvio que lhe outorgava um valor absoluto. Teria ele achado superior à ciência a alternativa que ele mesmo cita: uma cosmovisão "emocionalmente tranqüilizadora" ou "esteticamente satisfatória" (H EM PEL, 1960, p. 93)?

\section{R eferências}

BLOOR, D. Science and social imagery. Chicago/London: The U niversity of Chicago Press, 1991.

Bunge, M. Treatise on basic philosophy. v. 8: The good and the right. Dordrecht: D. Reidel, 1989.

Cupanı, A. A cerca do ethos da ciência. E pisteme, São Paulo, v. 3, n. 6, p. 16-38, 1998.

Dou GLAS, H. Inductive risk and values in science. Phil. Sci., v. 67, p. 559-579, 2000.

Feyerabend, P. A gainst method. London: Verso, 1994 [1975]. 
Graham, L. Between science and values. New York: Columbia U niversity Press, 1981.

H ARDING, S. The science question in feminism. Ithaca/ London: C ornell, 1993 [1986].

HEM PEL, C. Science and human values. In: . A spects of scientific explanation and other essays in the philosophy of science. London: The Free Press, 1970 [1960].

. Valuation and objectivity in science. In: COHEN, R. S.; LAUDAN, L. (Eds.), Philosophy and psychoanalysis. Boston: Reidel, 1983 p. 73-100.

Hesse, M. Theory and value in the social sciences. In: HokKwAY, Ch.; Pettit, P. (Eds.). A ction and interpretation. Cambridge: C ambridge U niversity Press, 1980 [1978].

InTEMAnN, K. Science and values: are value judgments always irrelevant to the justification of scientific claims?. Phil. Sci., v. 68, p. S506-S518, 2001.

LACEY, H. Is science value free? Values and scientific understanding. London-N ew York: Routledge, 1999.

LaUdAN, L. Science and values. Berkeley/ Los Angeles: U niversity of California Press, 1984.

LEISS, W. The domination of nature. Montreal/ Kingston: M CG illQ ueen's U niversity Press, 1994 [1972].

LongINo, H. Beyond 'bad science'. Science, Technology and Values, v. 8, n. 1, p. 7-17, 1983.

. Science as social knowledge. Princeton, NJ: Princeton Ũ niversity Press, 1990.

M CM ULLIN, E. Values in science. Edited by P. D. A squith and T. Nickles. Philosophy of Science A ssociation, v. 2, p. 3-28, 1983.

Merchant, $C$. The death of nature. San Francisco: Warper San Francisco, 1990 [1980].

Merton, Teoría y estructura sociales. M éxico: FCE, 1964. 
M itroff, I. The subjective side of science. Amsterdam/ N ew York: Elsevier, 1974.

M U LKAY, M. N orms and ideology. In: M U LKAY, M. Sociology of science. M ilton Keynes: O pen U niversity Press, 1991.

N AGEL, E. La estructura de la ciencia (The structure of science, 1960). Buenos Aires: Paidós, 1979.

RADNITZKY, G. La tesis de que la ciencia es una empresa libre de valores: ciencia, ética y política. In: Feyerabend, P.; Radnizky, G. Estructura y desarrollo de la ciencia. M adrid: Alianza, 1984.

Rescher, N. L os límites de la ciencia. Madrid: Tecnos, 1984.

Shaffer, N. Understanding bias in scientific practice. Phil. Sci. v. 63, p. S89-S97, 1996.

ZIM AN, J. Is science loosing its objectivity? N ature, v. 382, p. 751-754, 1996. 